\title{
Application of $e$ Tank for rainwater tank optimisation for Sydney metropolitan
}

\author{
$\underline{\text { M.A. Imteaz }}^{\text {a }}$, S.P. Akbarkhiavi ${ }^{\text {a }}$ and M.A. Hossain ${ }^{\text {a }}$ \\ ${ }^{a}$ Faculty of Engineering and Industrial Sciences, Swinburne University of Technology, Melbourne, \\ Australia. \\ Email: mimteaz@swin.edu.au
}

\begin{abstract}
One of several common water conserving techniques is on-site stormwater harvesting for nondrinking purposes. However there is a lack of knowledge on the actual cost-effectiveness and performance optimisation of any stormwater harvesting system. At present stormwater harvesting systems are proposed and installed without any in-depth analysis of its effectiveness in various climate conditions. In particular the proposed design storage volume could be overestimated or underestimated. The biggest limitation of stormwater harvesting schemes is the rainfall variability, which will control the size of the storage needed and can't be based on long-term average annual rainfall data. A stormwater harvesting system designed considering average annual rainfall will not provide much benefit for a critical dry period. Similarly, a stormwater harvesting design for a particular region will not be similar for stormwater harvesting design in other regions. With all these uncertainties, even with several awareness campaigns and financial incentives, there is a general reluctance to adopt any potential stormwater harvesting measure. The main reasons behind this are that people are not aware of the payback period for their initial investment and the optimum size of the storage required satisfying their performance requirements. It is necessary to quantify the expected amount of water that can be saved and used through any particular harvesting technique based on contributing catchment size, tank volume, geographic location, weather conditions and water demand.
\end{abstract}

eTank was developed based on daily water balance analysis, incorporating daily rainfall, contributing roof area and runoff generated from roof after losses (leakage and/or evaporation), daily water demand, tank storage capacity and overflow from the tank. Earlier eTank has been used for several reliability analyses within Melbourne metropolitan area to show ranges of rainwater tank outcomes depending on spatial and climatic variability. In order to assess reliability of domestic rainwater tanks in augmenting partial household water demand in Sydney area, the developed tool was used for three different climatic conditions (i.e. dry, average and wet years). In the earlier studies, a single representative year was selected for each of the dry, average and wet years. Dry, average and wet years were defined for the years having an annual rainfall of 10 percentile, 50 percentile and 90 percentile values respectively. However, as a particular year may have an unusual rainfall pattern, this study considered five respective years for each of the dry, average and wet years. eTank was used for the selected five years and average outcomes of five years were calculated. It is found that in some cases selection of a single year as dry/average/wet year lead to erroneous outcomes, as in some cases a particular dry year turned out to be better than a particular average year due to the fact that the selected average year was having some sporadic burst of rainfalls for which the storage capacity was insufficient.

To assess the spatial variability, the model was used for the performance analysis at two different regions of Sydney (Australia); Central and Western. These two regions of Sydney are characterised by notable different topography and rainfall characteristics. Rainwater tank outcomes (cumulative water savings, cumulative townwater supply and cumulative overflow) were presented and compared for these two regions for different climatic conditions.

Keywords: Rainwater tank, daily water balance, climatic conditions, eTank 


\section{INTRODUCTION}

With increasing population and changing climate regime, water supply systems in many cities of the world are under stress. To tackle this problem, water authorities are adopting several measures including demand management and identifying alternative water sources such as stormwater harvesting, greywater and wastewater reuse and desalination. Among all the alternative water sources, stormwater harvesting perhaps has received the highest level of attention. In Australia, government authorities have been promoting stormwater harvesting through campaigns, as well as offering incentives and grants to promote water saving ideas and innovations.

Among all the stormwater harvesting options, rainwater tanks have been most widely studied. Fewkes (1999) conducted studies on residential rainwater tanks in the United Kingdom, producing a series of dimensionless design curves which allows estimation of the rainwater tank size required to obtain a desired performance measure given the roof area and water demand patterns. Vaes and Berlamont (2001) developed a model to determine the effectiveness of rainwater tanks and stormwater runoff using long term historical rainfall data. Coombes and Kuczera (2003) found that for an individual building with a $150 \mathrm{~m}^{2}$ roof area and $1-5 \mathrm{~kL}$ tank in Sydney can yield 10-58\% mains water savings (depending on the number of people using the building). According to Coombes and Kuczera (2003), depending on roof area and number of occupants, rainwater tank use can result in mains water annual savings of $18-55 \mathrm{~kL}$ for $1 \mathrm{~kL}$ sized tanks and $25-144 \mathrm{~kL}$ for $10 \mathrm{~kL}$ sized tanks. In Sweden, Villarreal and Dixon (2005) investigated water savings potential of stormwater harvesting systems and noted that a mains water saving of $30 \%$ can be achieved using a $40 \mathrm{~m}^{3}$ sized tank (toilet and washing machine use only). Ghisi et al. (2007 and 2009) investigated the water savings potential from rainwater harvesting systems in Brazil and found that average potential for potable water savings to be 12 $79 \%$ per year for the cities analysed. Muthukumarran et al. (2011) found that use of rainwater inside a home in regional Victoria in Australia can save up to $40 \%$ of potable water use. Mun and Han (2012) developed a design and evaluation method for a rainwater harvesting system and concluded that a design based on sensitivity analysis and proper management of a rainwater harvesting system should be emphasized to improve the operation efficiency. Imteaz et al. (2012a) presented rainwater savings potentials and reliability of rainwater tanks in dry years for Southwest Nigeria. Souza and Ghisi (2012) presented detailed outcomes of rainwater harvesting potentials for thirteen different cities around the world. For their analysis, they have calculated average outcomes from long-term simulations using historical rainfall data. Rahman et al. (2012) analysed average wtaer savings, reliability and economic benefits of water savings in Sydney and they have found that the average annual water savings from rainwater tanks are strongly correlated with average annual rainfall. They also outlined that the benefit-cost ratios for the rainwater tanks are smaller than 1.0 without government rebate currently offered in some Australian cities. Mehrabadi et al. (2013) studied rainwater harvesting potentials and reliability for three different cities in Iran having three distinct climatic characteristics and they have summerised that rainwater tank reliabilities can significantly vary among different cities (within a coutnry) having different climatic conditions.

Despite positive outcome from many studies, there remains a general community reluctance to adopt stormwater harvesting including rainwater tanks on a wider scale. Part of the reason for this reluctance can be attributed to lack of information about the effectiveness of a stormwater harvesting system and the optimum storage size required to satisfy the performance requirements under the specific site conditions (Imteaz et al., $2011 \mathrm{~b}$ ). A proper in-depth understanding of the effectiveness of any proposed on-site stormwater harvesting system is often lacking. The predicted change in rainfall patterns in Australia as a result of global warming adds further complexity to planning adequate rainwater harvesting schemes. Furthermore, many studies have used mean annual rainfall data or generated rainfall data in modelling rainwater harvesting system. In an area of highly inter-annual rainfall variability, analyses considering long term mean annual rainfall may not be useful.

Eroksuz and Rahman (2010) investigated the water savings potential of rainwater tanks in multi-storied residential buildings for three cities in eastern Australia. They concluded that rainwater tank of appropriate size in a multi-storied building can provide significant water savings even in dry years. They also developed equations for predicting annual rainwater savings potentials for those cities. Khastagir and Jayasuriya (2010) analysed reliability of rainwater tanks and calculated the reliabililty using a daily water balance model. They produced contours of optimum tank sizes for surrounding areas of Melbourne, considering the historical daily rainfall, the demand for rainwater and the roof area for a supply reliability of $90 \%$. All of these analyses were based on historical daily rainfall data, making an average of cumulative historical savings and other model variables. Through such analysis of averaged variables/parameters rainwater tank users may not get an adequate insight of the expected realistic situation(s) in regards to variability and outcomes. With the impacts of climate change, such ranges of realitic outcomes are expected to be widen further. Furthermore, design 
charts (contours) presented by Khastagir and Jayasuriya (2010) are based on an expected reliability of $90 \%$. In reality, different user may opt for different reliability. Santos and Taveira-Pinto (2013) compared diffirent commonly used methods used for rainwater tank sizing while presenting case studies for Portugal. Imteaz et al. (2011c) developed a tool, eTank for the optimisation of rainwater tank size using daily water balance concept. This tool considered daily rainfall, losses due to leakage, spillage and evaporation, roof area, tank volume, rainwater demand, overflow losses and tank top-up requirements in case of shortage. The developed tool is also capable to calculate payback period of a particular tank installation and/or maintenance costs.

Imteaz et al. (2011a) presented a range of reliability charts for a central Melbourne location in relations to tank volume, roof area, total water demand and rainwater demand for extreme climatic conditions (driest and wettest years) in compared to an average year. However, as the driest and wettest years are very rare events, Imteaz et al. (2012b) later considered a more realistic representative dry and wet years; through statistical analysis of historical annual rainfall data, dry year is defined as having an annual rainfall value closer to $10^{\text {th }}$ percentile value and wet year is defined as having an annual rainfall value closer to $90^{\text {th }}$ percentile value. However, a particular year might have an unusual rainfall pattern compared to usual pattern of occurrences (i.e. sporadic bursts and/or longer dry periods). As such this study suggests considering 5 years of data for each of the dry, average and wet conditions.

\section{METHODOLOGY}

An earlier developed tool, eTank was used for the analysis of rainwater tank outcomes. eTank is a daily water balance model, which considers daily rainfall, contributing catchment (roof) area, losses (due to leakage, spillage and evaporation), storage (tank) volume and water uses for calculating rainwater tank outcomes; annual rainwater savings, annual overflow, annual townwater use and reliability. In the model, the primary input value is the daily rainfall amount for three differeent years (dry, average and wet years). The daily runoff volume is calculated from daily rainfall amount by multiplying the rainfall amount with the contributing roof area after deducting the losses. For this study, from the produced runoff, a $10 \%$ deduction was applied to account for several losses (leakage, spilling and evaporation). Generated runoff is diverted to the connected available storage tank. Available storage capacity is compared with the accumulated daily runoff. If the accumulated runoff is bigger than avaialble storage volume, excess water (overflow) is deducted from the accumulated runoff. Amount of water use(s) is deducted from the daily accumulated/stored runoff amount, if sufficient amount of water is available in the storage. In a situation, when sufficient amount of water is not avaialble in the storage, model assumes that the remaining water demand is met from the town water supply. The detailed mathematical procedures, formulations and logical sequences are outlined in Imteaz et al. (2011b, 2012a).

\section{DATA}

Historical daily rainfall data was collected from the Bureau of Meteorology, Australia for two different regions of Sydney; Western (Richmond UWS) and Central (Sydney Observatory). Table 1 summarises the important rainfall statistics for the two study regions. Mean rainfalls in Central and Western Sydney are $1302 \mathrm{~mm}$ and $906 \mathrm{~mm}$ respectively. Through statistical analysis of total annual rainfall data, three separate years were selected as dry year, average year and wet year. Selected years and corresponding annual rainfall values are shown in Table 2.

Table 1. Historical rainfall characteristics of the selected stations

\begin{tabular}{|l|c|c|}
\hline Variable & Western & Central \\
\hline Mean (mm) & 906.3 & 1302.2 \\
\hline Std. Dev. & 930.5 & 1287.6 \\
\hline Maximum (mm) & 264.3 & 323.6 \\
\hline Minimum (mm) & 679.1 & 881.5 \\
\hline
\end{tabular}

Table 2. Selected rainfalls and corresponding years for the dry, average and wet years

\begin{tabular}{|l|l|l|l|l|}
\hline & \multicolumn{2}{|c|}{ Western } & \multicolumn{2}{c|}{ Central } \\
\hline & $\begin{array}{l}\text { Rainfall } \\
(\mathrm{mm})\end{array}$ & Year & $\begin{array}{l}\text { Rainfall } \\
(\mathrm{mm})\end{array}$ & Year \\
\hline $\begin{array}{l}\text { Dry year } \\
(10 \text { percentile })\end{array}$ & 526.9 & 1901 & 822.9 & 1909 \\
\hline $\begin{array}{l}\text { Average year } \\
\text { (50 percentile) }\end{array}$ & 796.0 & 1953 & 1160.4 & 1876 \\
\hline $\begin{array}{l}\text { Wet year } \\
(90 \text { percentile) }\end{array}$ & 1172.0 & 1978 & 1650.8 & 1934 \\
\hline
\end{tabular}

For the selection of 5 years' data, for each of the conditions four additional years were selected in a way that out of these four years, two years are having annual rainfall amounts immediately higher and two years are having annual rainfall amounts immediately lower than the rainfall amounts of above selected years. An 
average non-potable water demand of $150 \mathrm{~L} /$ person/day was considered, where the average total demand of water for the New South Wales residents is $230 \mathrm{~L} /$ person/day.

\section{RESULTS}

eTank was used for all the selected years for different combinations of tank sizes, roof areas and demands.

\subsection{Assessment on Data Selection (1 year vs. 5 years data)}

For the primary assessment, justification of using 5 years' data in lieu of using single year data has been investigated. Several combinations of data were investigated and in most of the cases outcomes using average of 5 years data and single year data are very similar. However, in some cases it was found that consideration of a single year may lead to erroneous results due to the selection of an unusual year based on annual total rainfall. For such irregular years, it may happen that a dry/average year is producing better results than an average/wet year. Figure 1 shows the cumulative townwater use graphs for Western Sydney for a two-people household scenario having roof area of $200 \mathrm{~m}^{2}$ and tank volume of $7500 \mathrm{~L}$ under three climatic conditions using both the single year data and 5 years data. For this particular case, it is found that using single year data cumulative townwater use in an average year is higher than a dry year, which is not logical. However, using 5 years data, same outcomes become logical; i.e. townwater uses in average year is lower than the dry year and higher than the wet year. Based on the above finding it is recommended that instead of using a single year data, 5 years data should be used and then averaged for the calculations of different rainwater tank outcomes. As such in all the subsequent analysis, for a particular climate scenario 5 years data was used.

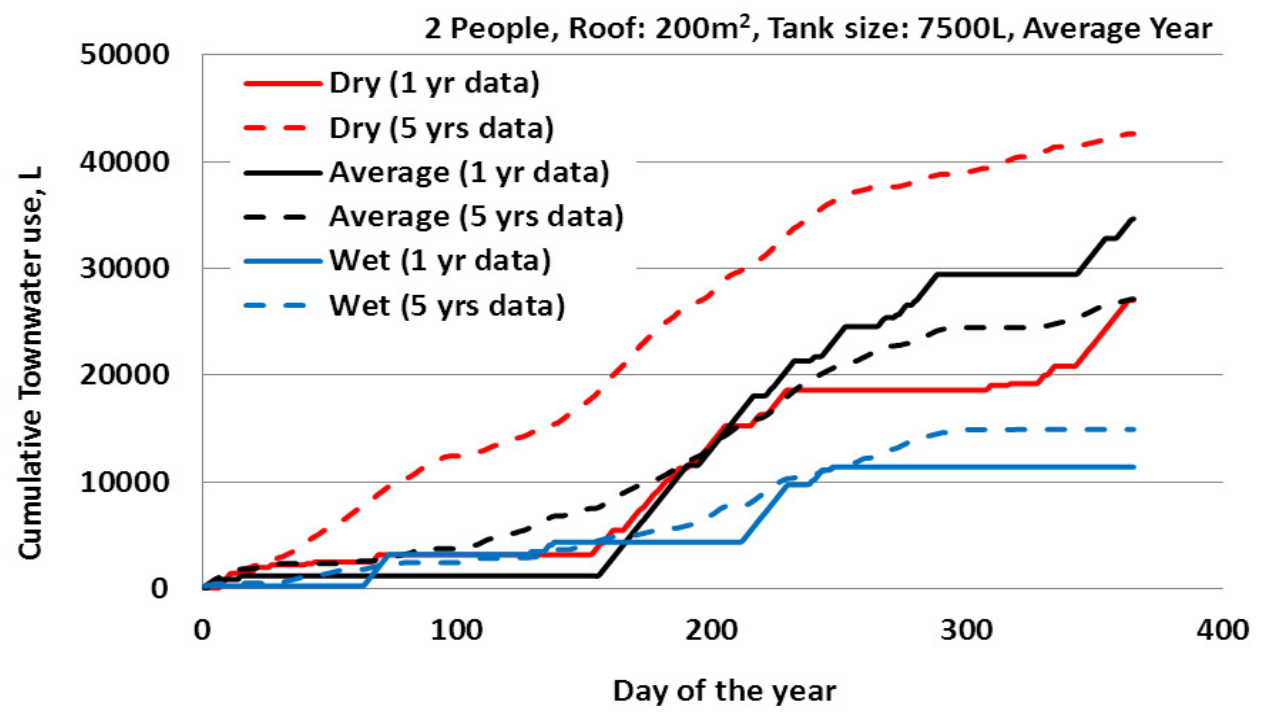

Figure 1. Analysis on cumulative townwater uses using 1 year and 5 years average data

\subsection{Spatial and Climatic Variability}

In majority of the rainwater tank studies single outcomes are presented for a city, and most of them dealt with an average rainfall or simulating models for total available record length (usually many years) and then averaging the total outcomes. However, climatic variations are expected to be significant. Also, for large cities the spatial variations are expected to be significant. Imteaz et al. (2013) presented large variations of rainwater tank outcomes for Melbourne. Figure 2 shows spatial variations within central and western Sydney in regards to townwater use for the same conditions ( 2 people household, roof area: $200 \mathrm{~m}^{2}$ and tank volume: 7500L). Figure 2 shows significant differences in required townwater among the two locations; dry year townwater requirement for central Sydney is very close the wet year townwater requirement for western Sydney and dry year townwater requirement for western Sydney is 25,000L more than the dry year townwater requirement for central Sydney.

Figure 3 shows the differences in expected water savings potentials within central and western Sydney for different tank sizes under two different climatic conditions (dry and wet). Some significant variations are observed from the figure. However, for this case climatic variation is more prominent than the spatial variation. For western Sydney a maximum difference in water savings of 10,000L is expected within dry and 
wet years. Also, in dry years spatial variation is more significant than the spatial variation in wet years. For bigger tank sizes $(>8000 \mathrm{~L})$, water savings for western Sydney in wet years are very close to water savings for central Sydney in dry years. This is because with the higher rainfall amounts and sufficiently bigger tanks and roofs, rainwater tanks will have maximum savings with a moderate demand. However, if the demand is very high, this variation is expected to grow bigger. These outcomes reveal an important decision making need for the tank owner. Different tank owner may opt for different tank and connecting roof sizes, and compromise the need of townwater augmentation. eTank would be useful tool for such decision making.

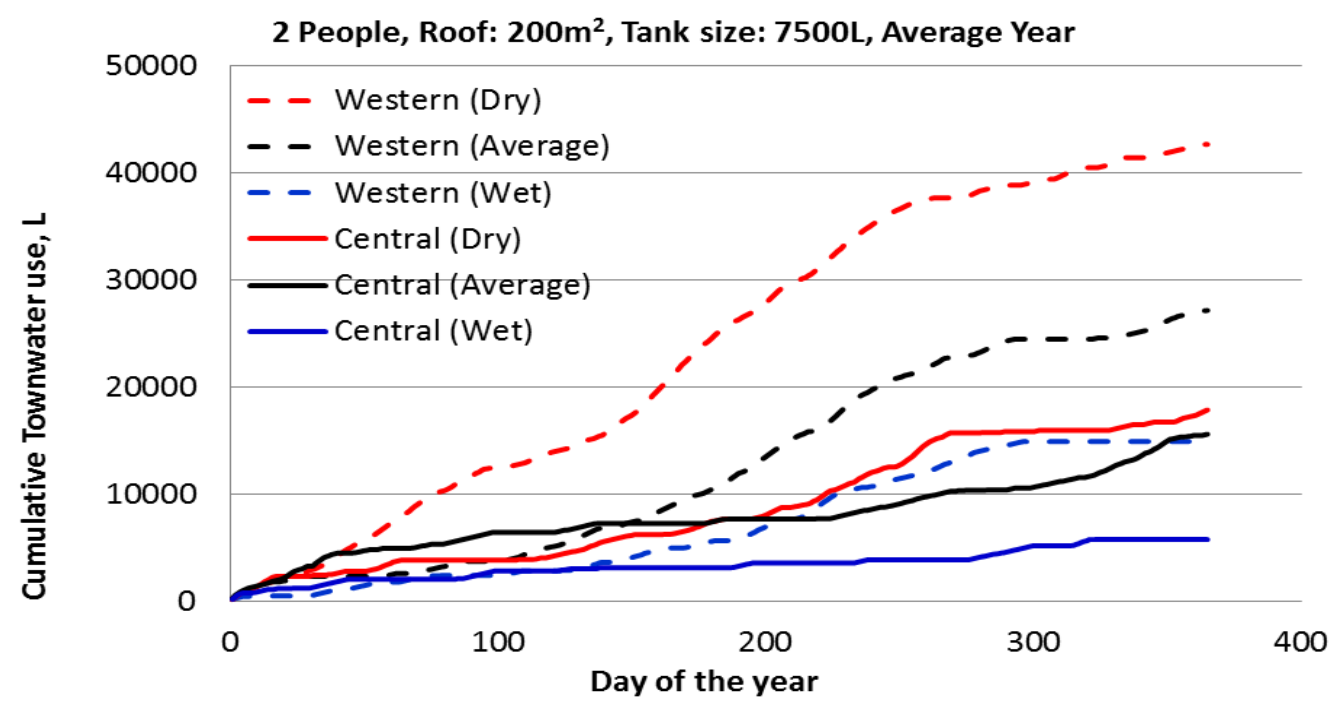

Figure 2. Comparison of cumulative townwater uses between central and western Sydney

2 People, Roof: $200 \mathrm{~m}^{2}$

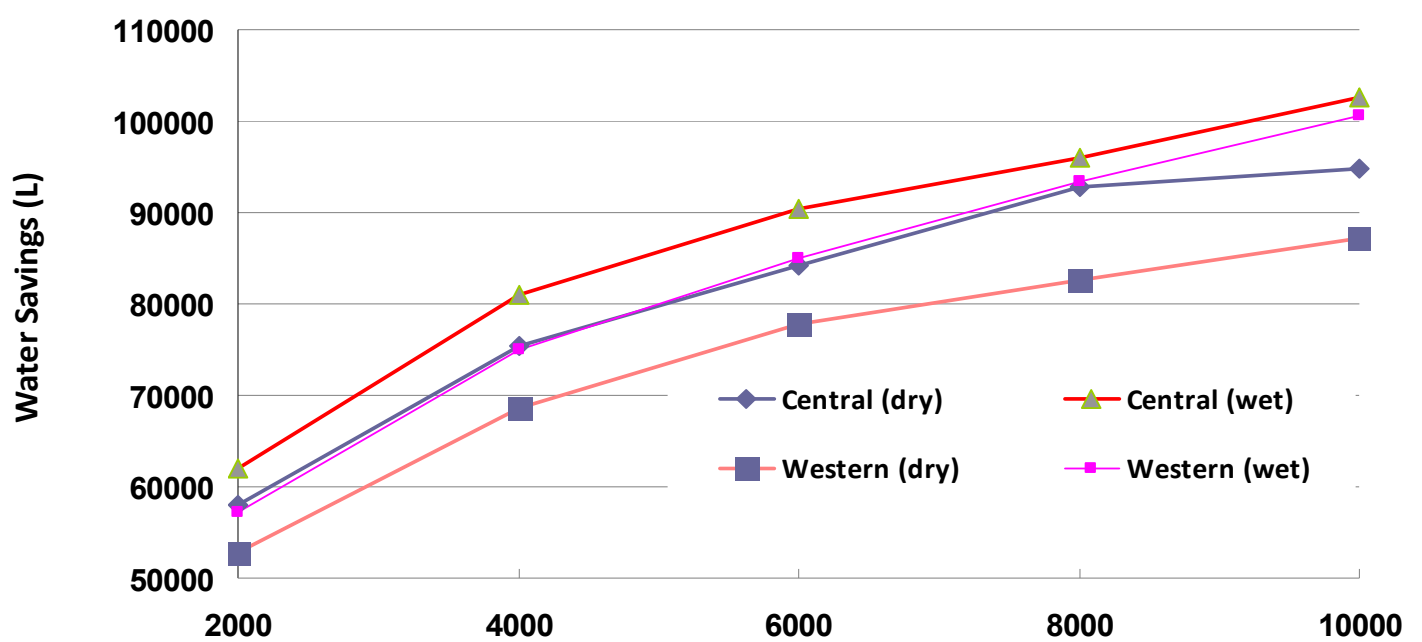

Tank Size (L)

Figure 3. Comparison of cumulative townwater uses between central and western Sydney

\subsection{Reliability}

Reliability is another parameter, which needs to be considered in rainwater tank outcomes analysis. A tank might be able to save good amount of total annual water, however may not be able to supply intended daily demand throughout the year. Reliability is defined as the percentage of number of days in a year when the rainwater is able to supply intended daily demand. For all the rainwater tank installations it is necessary to have an alternate supply augmentation (i.e. townwater) in case of lengthy dry periods. However, most of the owners would not like to depend too much on this townwater, because of cost and maintenance burdens on plumbing, switching/power requirements for any augmentation system. On top of these, a risk of system 
failure/mal-function is there. As such, from owners' point of view it is highly desirable to achieve reliability close to $100 \%$. Figure 4 shows the spatial and climatic variations of reliabilities for a 2 people demand ( 300 $1 /$ day) and $200 \mathrm{~m}^{2}$ roof for different tank sizes. It is found that for the assumed conditions in western Sydney, it is not possible to achieve $100 \%$ reliability even with a tank size of $10,000 \mathrm{~L}$. However, for central Sydney with the same conditions reliability close to $100 \%$ is achievable even with a tank size of $6,000 \mathrm{~L}$. Also, it is found that in regards to reliability, spatial and climatic variations are much higher than for the similar conditions with water savings. Within central and western Sydney, reliabilities vary approximately $13 \%$ and within climatic conditions reliabilities vary $7 \sim 17 \%$ depending on the locations.

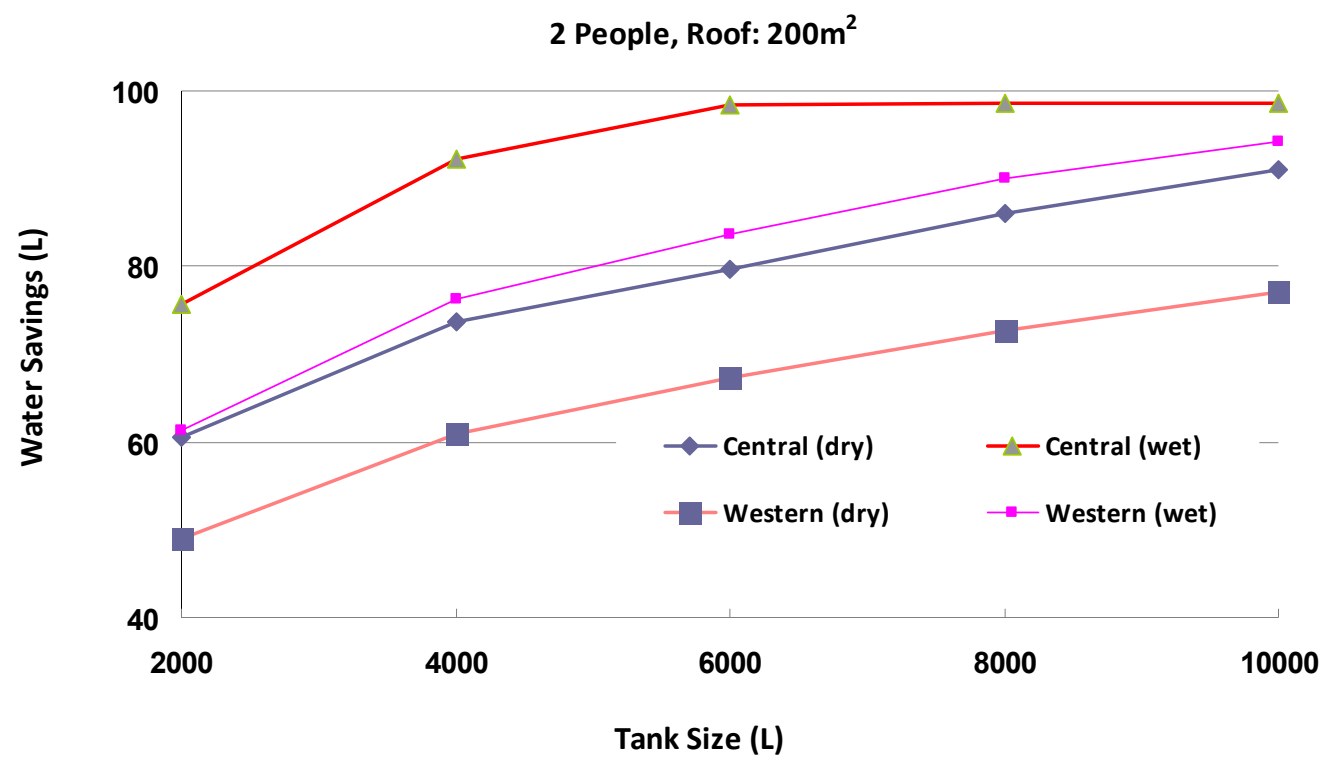

Figure 4. Climatic and spatial variations of reliabilities

\section{DISCUSSION AND CONCLUSIONS}

This paper investigates rainwater tank outcomes including reliability at two different regions (central and western) of Sydney, under different scenarios i.e. climatic conditions and tank volumes. Traditional rainwater tank analysis mostly involves considering single (i.e. mean annual rainfall data or daily rainfall data for an average year) rainfall data or calculating for many years data, then averaging outcomes of many years data. In an area of highly inter-annual rainfall variability, analysis considering long term mean annual rainfall or averaging many years outcomes my not be useful. This study emphasizes such analysis for three climatic conditions (i.e. dry, average and wet). Past studies on this considered a single year's daily rainfall data for each of the dry, average and wet years. This paper showed that considering only a single year's data may lead to erroneous results, as a selected year might be a very typical year, not representing average trend. As such, this study recommends using five years data for each of the climatic conditions. Consideration of five years data is expected to eliminate the effect of any unusual year in consideration.

It is found that significant climatic and spatial variaions are expected for townwater augmentaion requirement, water savings and reliability. for a relatively smaller tank size $(<10,000 \mathrm{~L}), 100 \%$ reliability cannot be achieved even in a wet year. Also, it is found that rainwater savings and reliabilities for central Sydney are much higher than the expected water savings and reliabilities for western Sydney. The considered rainfall stations produced significantly different results due to the difference in topographic conditions and rainfall variability. The results reveal that rainwater tank outcomes (i.e. watere savings, townwater need and reliability) can vary significantly within a large city like Sydney and emphasizes the need to change the design practice of considering a single annual rainfall value for the purpose of rainwater tank sizing. The results outlined in this study would vary with geographical locatoins i.e. with different climatic conditions or in general with different rainfall intensities and pattern. In reality, there are numerous optimal solutions with different combinations of storage volumes, roof sizes and rainwater demands. eTank would be a very handy tool to assess expected reliability, cumulative water savings, cumulative overflow losses and cumulative required townwater supply for any geographical location under any tank-roof-demand conditions, which will make owners' decision making process easy and knowlegable. 
Imteaz et al., Application of eTank for Rainwater Tank Optimisation

\section{REFERENCES}

Coombes, P., Kuczera, G. (2003). Analysis of the performance of rainwater tanks in Australian capital cities. 28th International Hydrology and Water Resources Symposium, Wollongong, NSW, Australia.

Eroksuz, E., Rahman, A. (2010). Rainwater tanks in multi-unit buildings: A case study for three Australian cities. Resources Conservation and Recycling, 54, 1449-1452.

Fewkes, A. (1999) The use of rainwater for WC flushing: the field testing of a collection system. Building and Environment, 34(6), 765-772.

Ghisi, E., Bressan, D.L., Martini, M. (2007) Rainwater tank capacity and potential for potable water savings by using rainwater in the residential sector of southeastern Brazil. Building and Environment, 42, 16541666.

Ghisi, E., Tavares, D.F., Rocha, V.L. (2009) Rainwater harvesting in petrol stations in Brasilia: Potential for potable water savings and investment feasibility analysis. Resources Conservation and Recycling, 54, 7985.

Imteaz, M.A., Adeboye, O., Rayburg, S., Shanableh, A. (2012a) Rainwater harvesting potential for southwest Nigeria using daily water balance model. Resources Conservation and Recycling, 62, 51-55.

Imteaz, M.A., Ahsan, A., Naser, J., Rahman, A. (2011a) Reliability Analysis of Rainwater Tanks in Melbourne using Daily Water Balance Model. Resources Conservation and Recycling, 56, 80-86.

Imteaz, M.A., Ahsan, A., Shanableh, A. (2013) Reliability analysis of rainwater tanks using daily water balance model: Variations within a large city. Resources Conservation and Recycling, 77, 37-43.

Imteaz, M.A., Rahman, A., Ahsan, A. (2012b) Reliability analysis of rainwater tanks: A comparison between South-East and Central Melbourne. Resources Conservation and Recycling, 66, 1-7.

Imteaz, M.A., Rauf, A., Aziz, A. (2011b) eTank: A decision support tool for optimizing rainwater tank size, International Congress on Modelling and Simulation MODSIM, Perth, Australia.

Imteaz, M.A., Shanableh, A., Rahman, A., Ahsan, A. (2011c) Optimisation of Rainwater Tank Design from Large Roofs: A Case Study in Melbourne, Australia. Resources Conservation and Recycling, 55, 10221029.

Jenkins GA. (2007) Use of continuous simulation for the selection of an appropriate urban rainwater tank. Australian Journal of Water Resources, 11(2), 231-46.

Khastagir, A., Jayasuriya, N. (2010) Optimal sizing of rain water tanks for domestic water conservation. Journal of Hydrology, 381, 181-188.

Mehrabadi, M.H.R., Saghafian, B., Fashi, F.H. (2013) Assessment of residential rainwater harvesting efficiency for meeting non-potable water demands in three climate conditions. Resources Conservation and Recycling, 73, 86-93.

Mun, J.S., Han, M.Y. (2012) Design and operational parameters of a rooftop rainwater harvesting system: definition, sensitivity and verification. Journal of Environmental Management, 93, 147-153.

Muthukumaran, S., Baskaran, K., Sexton, N. (2011) Quantification of potable water savings by residential water conservation and reuse - A case study. Resources Conservation and Recycling, 55, 945-952.

Rahman A., Keane J., Imteaz M. A. (2012) Rainwater harvesting in Greater Sydney: Water savings, reliability and economic benefits. Resources Conservation and Recycling, 61, 16-21.

Santos, C., Taveira-Pinto, F. (2013) Analysis of different criteria to size rainwater storage tanks using detailed methods. Resources Conservation and Recycling, 71, 1-6.

Souza, E.L., Ghisi, E. (2012) Potable Water Savings by Using Rainwater for Non-Potable Uses in Houses. Water, 4(3), 607-628.

Vaes, G., Berlamont, J. (2001) The effect of rainwater storage tank on design storms. Urban Water, 3, 303307.

Villarreal, E.L., Dixon, A. (2005) Analysis of a rainwater collection system for domestic water supply in Ringdansen, Norrkoping, Sweden. Building and Environment, 40, 1174-1184. 